DOI: https://doi.org/10.47405/mjssh.v6i9.956

\begin{tabular}{|c|c|}
\hline 4 & Malaysian Journal of Social Sciences and Humanities (MJSSH) \\
\hline $\begin{array}{l}\text { Malaysian Juoural of } \\
\text { Social ccciecces and }\end{array}$ & Volume 6, Issue 9, September 2021 \\
\hline (MJ-sSH) & e-ISSN : 2504-8562 \\
\hline & $\begin{array}{l}\text { Journal home page: } \\
\text { www.msocialsciences.com }\end{array}$ \\
\hline
\end{tabular}

\title{
Food Borne Disease and the Lifestyles of the Students and Food Handlers in Rural Schools: A Preliminary Observation
}

Song Jing, L. ${ }^{1}$, Hassan, Z. ${ }^{1}$, Regina, G. ${ }^{1}$

1Universiti Malaysia Sarawak (UNIMAS)

Correspondence: Song Jing, L. (songjing_1992@yahoo.com)

\begin{abstract}
Food borne diseases cause millions of deaths every year around the world. The major factors contributing to food borne diseases and the prevalence of food poisoning among students are the food preparation process, lifestyles, physical cleanliness and water supplies. Food mismanagement by food handlers and students' and food handlers' poor knowledge of food hygiene are the factors that lead to food poisoning among school students. The objectives of this study are to: investigate how food handlers carry out food preparation; determine students' and handlers' standards of food hygiene assess the physical cleanliness of school canteens and the purity of their water supplies; and develop guidelines for the prevention of food poisoning. The aspects investigated in this study are the food preparation process, knowledge of food hygiene, physical cleanliness and food poisoning prevention methods.
\end{abstract}

Keywords: food borne diseases, food handlers, food preparation process, food poisoning prevention and physical cleanliness

\section{Introduction}

Food borne diseases such as cholera, typhoid fever, hepatitis A, dysentery and food poisoning occur because of consumption of foods contaminated with chemicals and microorganisms (Sharifa Ezat, Netty \& Sangaran, 2013). Salmonella bacteria are the main cause of food borne illnesses around the world and they are normally are transmitted to humans through consumption of contaminated food of animal origin, such as eggs, chicken, meat and milk (World Health Organization, 2019). This study focuses on food borne diseases, and particularly on food poisoning, among school students. Food borne diseases causes and lifestyles are interrelated (Sharifa Ezat, Netty \& Sangaran, 2013). The increase in the incidence of food poisoning may be because food handlers ignore the importance of safe food handling and the correct way to prepare food in the kitchen (Abdul-Mutalib et al., 2015). Studies in New Zealand found food handling practices still to be the main threat circumstance for food borne diseases. Therefore, the causes of poor practices need to be investigated (Al-Sakkaf, 2013). School premises are checked and school food handlers have been trained to practice safe food handling but food poisoning outbreaks still occur (New et al., 2017). In Malaysia different ethnic groups practise different food preparation approaches and hygiene directly associated with the sociocultural differences and dietary and culinary practices of each group (Sharifa Ezat, Netty \& Sangaran, 2013). Data from sociological approaches are needed to take account of the populations' food habits and beliefs and identify the influences on food safety in the population (Ehiri \& Morris, 2013). This 
kind of data is important to develop a disease control message which can effect behavioral change and can be applied in the development of future food safety training modules.

Statistics provided by Pejabat Kesihatan Betong indicated that in Sarawak Betong is the location where the most food poisoning cases occurred. In Sarawak, the incidence of reported cases of food poisoning was higher among Malay students than Iban students (Health Informatics Centre, Ministry of Health Sarawak, 2018). Data obtained from Pejabat Kesihatan Daerah Betong (2019) for instance, shows that Malay students under 18 years old accounted for 113 out of the 183 cases reported during 2017 and 137 out of the 148 cases reported during 2018 (Pejabat Kesihatan Daerah Betong, 2019). In 2010 approximately 3,822 cases were reported; this figure increased to 5,265 cases in 2013. The highest number of food poisoning cases $(8,000)$ was in 2015 . As school students represent the majority of food poisoning cases, they can be considered particularly vulnerable to food poisoning, and the consumption of contaminated food from school canteens may be implicated. The statistics motivated the researcher to study schools' food preparation processes and food handlers' practices.

\section{Literature Review}

\section{The Processes of Food Preparation and their Hygienic Safety}

Food handlers did not follow safe food preparation practices. They prepared foods too early before consumption, i.e. in the morning or even the day before, allowing bacteria to grow due to high humidity levels and temperatures (Collins, 1997). Moreover, food handlers practised poor personal hygiene in food preparation. Mishandling and poor refrigeration of foodstuffs were the main causes of contamination (Collins, 1997). Another issue was the lack of safe food preparation facilities resulting, for example, in cross-contamination of raw and cooked foods and contaminated utensils and plates (Venter, 2000).

Collins (1997) noted that demographic and consumer lifestyles affect the way food is prepared and stored. There is evidence that lack of time to prepare food, preparation of food too early, improper storage temperatures and poor personal hygiene during food preparation were the main causes of contamination. Lack of awareness of the dangers of storing food at the wrong temperature in refrigerators could lead to food borne diseases (Johnson, Donkin, Morgan et al., 1998). Most reported cases of food borne diseases are due to improper storage, inadequate cooking and cross-contamination (Kennedy et al., 2005). Food handlers lack knowledge as to the correct temperatures for food storage and preparation and acceptable methods to thaw frozen foods. Good temperature control is crucial to keep foods fresh and food kept at the wrong temperature may be subject to contamination (Sharif, Obaidat \& Al-Dalalah, 2013).

Studies (Dora-Liyana et al., 2018; Venter, 2000) showed that food poisoning occurred mostly in schools. They suggested that the short time available for the mass preparation of meals daily in a conventional kitchen may have contributed to this (Dora-Liyana et al., 2018). Food handlers tend to prepare the food early in the morning or even the day before, probably increasing the incidence of bacterial growth in food, leading to food poisoning. Most cases of food poisoning are caused by temperature and time abuse, improper thawing methods, improper food holding temperatures and refrigeration equipment malfunction (Dora-Liyana et al., 2018). The study found that basic food handling practices such as food handlers' routines in schools were missing. Venter (2000) pointed out the lack of safe food preparation facilities. Refrigerators, cooking utensils and equipment in good condition, are crucial to keeping raw materials fresh and safe.

Mjoka \& Selepe, 2018 found that most food handlers do have knowledge of hygienic practices, but just don't apply that knowledge. Most, but not all food handlers do practise hygiene. The issue of why food handlers do not apply their good knowledge of hygiene and comply with good hygiene standard operation procedures (SOPs) captured the researcher's attention. 


\section{Knowledge, Attitudes and Behaviours Concerning Hygiene in Food Preparation Practices}

The level of hygiene awareness among the students and food handlers is exemplified by their knowledge, attitudes and behaviours towards hygiene. Food handlers and students have low levels of awareness of hygiene. Therefore, the food poisoning cases among school students remain high. It is important to understand the human behaviours related to food preparation practices to avoid food poisoning.

Earlier studies related to hygiene awareness and food handling (Dora-Liyana et al., 2018; Venter, 2000) found that food handlers have a poor attitude and lack of knowledge concerning hygiene in food preparation. Venter (2018) found that dietary habits, such as the consumption of raw or hazardous foods for rituals and cultural beliefs, cause food borne diseases. Dora-Liyana et al. (2018) also found that preparing food too early, improper thawing methods, improper food holding temperatures and refrigeration equipment malfunction caused food poisoning. Moreover, food handlers showed low levels of personal cleanliness, for instance, not keeping fingernails short or covering the hair with a cap. They often ignored the correct handwashing steps, handled foods without using masks and gloves, and talked while handling food (Dora-Liyana et al., 2018). Food handlers lacked knowledge of how to keep equipment hygienic (for example, they reused dish towels to wipe plates) and the use of different chopping board for raw and cooked foods to prevent cross contamination.

A report by Institut Penyelidikan Tingkahlaku Kesihatan (IPTK) in 2017 stated that the Ministry of Health Malaysia (MOH) concluded that food handlers did not strictly follow the MOH's safe food preparation guidelines. Furthermore, the food handlers' and students' awareness of hygiene is poor or lacking - they may not be aware of the correct temperatures for food storage and preparation and how to thaw frozen foods (Sharif, Obaidat \& Al-Dalalah, 2013). Dora-Liyana et al. (2018) reported that food handlers overcame the shortage of food preparation time available by mass preparation of meals or preparation a day earlier. They also found food handlers to have poor standards of personal hygiene and to lack knowledge of equipment hygiene, so, for example, they reused dish towels to wipe plates, leading to food contamination. Moreover, dietary habits, such as consumption of raw or hazardous foods for rituals and cultural beliefs, also resulted in exposure to contaminated food (Venter, 2000). Food handlers should comply strictly with the standard operation procedures (SOPs) set by the Ministry of Health to reduce and prevent food poisoning in schools. MOH should strengthen and strictly enforce knowledge and awareness of food hygiene among food handlers. The practice of preventative behaviour by food handlers and students is crucial to prevent food poisoning.

Soon, Singh \& Bains (2011) claimed that unhygienic food handling and lack of cleanliness in food preparation, people's poor hygienic practices and insanitary food handling procedures, and knowledge and attitudes towards food safety need to be emphasized to reduce food borne diseases in schools.

Abdul-Mutalib et al. (2015) suggested that insanitary food handling procedures contributed to more than $50 \%$ of reported food poisoning cases. They stated that contamination would occur when meat came into contact with animal skin, fur or intestines in the kitchen during food preparation due to mishandling because food handlers ignored the correct way to prepare foods and did not keep practise a high standard of kitchen hygiene as regards cooking utensils and kitchen counters. They also noted that consumers preferred to buy cheap food, not considering whether it is hygienic and safe to eat.

Food handlers had poor personal cleanliness: keeping fingernails short and covering the hair with a cap are crucial practices to prevent cross-contamination. A lack of knowledge of the correct steps for effective handwashing, no use of anti-bacterial soap, handling and distributing foods without using gloves or masks and talking while handling food are some examples (Dora-Liyana et al., 2018).

Food handlers lacked knowledge of equipment hygiene and reused dish towels to wipe plates, which is not allowed due to the potential for cross-contamination (Dora-Liyana et al., 2018). Raw and cooked foods should be kept separate, for example by using a different chopping board for cutting meats and for cutting vegetables. 
Ehiri and Morris (2013) cite the lack of use of information on sociocultural influences on food safety. Food habits and beliefs of a population are crucial. There is a need to apply sociological methods, such as identification of impacts on food safety in a population, in future training programs in order to change human behavior. Safe food preparation practices are often associated with kitchen culture, safe food guidelines and practices and a better understanding of beliefs, practices and cultural values is needed to upgrade existing guidelines and practices. A knowledge gap regarding sociocultural aspects of food poisoning prevention is apparent: one example is Malay food handlers' cultural values, beliefs and practices in respect of food preparation. The researcher found that currently training does not take these aspects into consideration.

Venter (2000) found that dietary habits such as consumption of raw or hazardous foods for rituals and cultural beliefs cause food borne diseases. Cowan (2019) found that food handlers did not pay strict attention to personal hygiene while Sharifa Ezat, Netty \& Sangaran, (2013) noted a lack of education in the basic rules for hygienic food preparation. The findings could be related to genetic or sociocultural differences between ethnic groups related to dietary and culinary practices. For example, Sharifa Ezat, Netty \& Sangaran (2013) found that the Hmong community in China has little knowledge of food borne diseases and community cultural practices involve poor food storage and preparation, thus increasing the risk of food poisoning. Moreover, the Chinese community has the lowest rate of acute diarrhoea among various races because most of their food is usually served hot from the wok. The food is cooked and consumed immediately, reducing the risk of food poisoning (Sharifa Ezat, Netty \& Sangaran, 2013).

\section{Physical Cleanliness and Food Hygiene}

Physical cleanliness, or the cleanliness of the environment where food is prepared and served, is important and food handlers need to give this strong emphasis. Waste management, (food and solid waste) can result in food contamination when food waste is dumped down drains or in uncovered bins. Kitchen surfaces and floors should be cleaned continuously, before, during and after food preparation (Norazla \& Nor Atirah, 2019).

The food should be covered and protected from flies, mice, cockroaches and dust and the right utensils, rather than the hands, used to pick up the food. Foods should not be put on, or prepared on the floor, but on a clean table (Bahagian Keselamatan dan Kualiti Makanan (MOH), 2020).

Most rural schools have poor and unhygienic physical environments and water supplies contributing to food contamination. Adams et al. (2009) claimed that inadequate water supplies, sanitation and a lack of handwashing among students in rural schools contributed to food poisoning. In addition, food handlers have been ignoring the importance of safe food handling in the kitchen (Abdul-Mutalib et al., 2015). Ignorance of food safety principles and practices among food handlers and students will cause major health problems. A clean and hygienic kitchen and environment is significant in the effective prevention of food borne diseases.

An adequate water supply, sanitation and hygiene in schools are important for disease prevention. Adams et al. (2009) found that diseases are prevalent in many schools in rural areas of because of inadequate water supplies, sanitation and hygiene and particularly a lack of handwashing.

Abdul-Mutalib et al. (2015) stated the kitchen and its surroundings should be kept clean and free from dirt, flies and germs. The cooking utensils, plates, cups and other utensils should be kept clean. Waste should be disposed of in dedicated trash cans provided with lids. Other factors to consider are protection of the water source, proper disposal of solid waste and excreta, wastewater drainage, banning animal rearing in the vicinity of kitchens, and environmental hygiene in general. The lack of a clean water supply and an unhygienic environment will lead to cases of food poisoning. Food handlers have been ignoring the importance of safe food handling in the kitchen (Abdul-Mutalib et al., 2015). 
Some food handlers were found to practise good physical cleanliness. Tan et al., (2013) found food handlers in selected schools demonstrated that they had basic knowledge on good personal hygiene. Not many studies have been done on this particular issue.

\section{Food Poisoning Prevention}

Food poisoning can be prevented if the storage of food at below 40 -degree Celsius $\left({ }^{\circ} \mathrm{C}\right)$ within four hours after preparation (Hurst, 2010). Good personal hygiene and good hand washing habits are essential in preventing contamination. For example, food handlers must avoid hand contact with cooked foods. Good sanitation practices can prevent cross contamination. Raw and cooked foods should be prepared separately on different equipment (Tan et al., 2013). Regular hand-washing is the best way to contain the spread of food borne diseases. The effective steps in preserving food are handwashing, thorough cooking, keeping raw and cooked foods separate, storage and proper refrigeration and throwing out of spoiled foods (Dennis, 2014).

Food poisoning can be prevented if food handlers and students comply strictly with the rules. For instance, food handlers must wash their hands before they handle food and always during food preparation. Food handlers must separate raw and cooked foods by the use of different chopping board and utensils (Ramful \& Menon, 2017). In addition, food handlers must cook food at high temperatures to kill all the microorganisms. Next, food handlers must store the food in a refrigerator at the correct temperature. It should be compulsory for food handlers to wear a mask and gloves during food preparation (Ramful \& Menon, 2017). Students must wash their hands and use hand sanitizer regularly to make sure their hands are free of viruses and bacteria before they consume food. According to Ramful \& Menon (2017), food borne diseases can be prevented with proper food handling and maintenance of good practices and hygiene. Food poisoning can be prevented to the extent that handlers and students comply with food safety rules and food poisoning prevention practices.

Food borne disease is preventable with proper food handling and a focus on good practices and hygiene (Ramful \& Menon, 2017). The five methods to safe food practices are: wash hands before handling food and always during food preparation; separate raw and cooked foods; cook food thoroughly for two minutes at about $70^{\circ} \mathrm{C}$ to kill all microorganisms; store food in a refrigerator at a safe temperature (about $5^{\circ} \mathrm{C}$ ); use safe water and raw materials.

In addition, food handlers should practice good hygiene: use the right refrigerator temperature for chilling and storage, wear gloves and a mask to maintain personal hygiene, only prepare food when in good health and wash hands regularly (Ramful \& Menon, 2017).

\section{Conclusions}

The lack of time to prepare food or preparation of food too early causes food poisoning to occur. Improper storage temperatures and food handlers' poor personal hygiene, lack of knowledge on how to handle foods, and mishandling of foods cause food contamination leading to food poisoning. Lack of safe food preparation facilities and poor refrigeration of foodstuffs in the kitchen and school canteen are other relevant issues. Another issue was the failure to use sociocultural information related to food handlers' cultural values, beliefs, and practices regarding food preparation. The findings could be related to genetic or socio-cultural differences between ethnic groups related to dietary and culinary practices. Training does not take cultural values into consideration. Furthermore, the basic food handling practices in terms of food handlers' guidelines and routines in schools were missing. The study will attempt to fill the gaps.

\section{References}

Abdul-Mutalib, N.A., Syafinaz, A. N., Sakai, K., Shirai, Y. (2015). An overview of foodborne illness and food safety in Malaysia. International Food Research Journal, 22(3), 896-901. 
Adam, J., Bartram, J., Chartier, Y., Sims, J. (2009). Water, Sanitation and Hygiene Standards for Schools in Low-cost Settings. Geneva, Switzerland: World Health Organization Publication.

Al-Sakkaf, A. (2013). Domestic food preparation practices: a review of the reasons for poor home hygiene practices. Oxford University Press, 30(3), 427-437.

Bahagian Keselamatan dan Kualiti Makanan, 2020. Amalan-amalan Mengelakkan Keracunan Makanan di Sekolah.

Collins, J. E. (1997). Impact of changing consumer lifestyles on the emergence/reemergence of foodborne pathogens. Emerging Infectious Diseases, 3(4), 471-479.

Cowan, K. (2019). Public-health aspects of food poisoning. Cambridge University Press, 16(2), 136140. Retrieved from https://doi.org/10.1079/PNS19570033

Dennis, E. (2014). Food Poisons; Causes, Effects, and Prevention. International Conference on Education and Social Sciences. 613.pdf (ocerints.org)

Dora-Liyana, A. L., Mahyudin, N. A., Ismail-Fitry, M. R., Ahmad-Zaki, A., Rasiyuddin, H. (2018). Food Safety and Hygiene Knowledge, Attitude and Practices among Food Handlers at Boarding Schools in the Northern Region of Malaysia. International Journal of Academic Research in Business and Social Sciences, 8(17), 238-266.

Ehiri, J. E., Morris, G. P. (2013). Hygiene training and education of food handlers: Does it work? Taylor \& Francis: Routledge, 35, 243-251.

Health Informatics Centre. Ministry of Health Malaysia. (2018). Health Indicators 2018. Retrieved from

file:///C:/Users/Administrator/Desktop/LR\%20ON\%20FOOD\%20POISONING/sampling\%20te chniques/salmonella\%20and\%20food\%20poisoining\%20journals/Petunjuk_Kesihatan_2018ne w.pdf

Hurst, W. (2010). Preventing Food Poisoning and Food Infection. University of Georgia Cooperative Extension Bulletin. Preventing Food Poisoning and Food Infection (uga.edu)

Johnson, A. E., Donkin, A., Morgan, K., Lilley, J., Neale, R., Page, R., Silburn R. (1998). Food safety knowledge and practice among elderly people living at home. Epidemiology Community Health, $52,745-748$.

Kennedy, J. Jackson, V., Blair, I. S., McDowell, D. A., Cowan, C., Bolton, D. J. (2005). Food Safety Knowledge of Consumers and the Microbiological and Temperature Status of their Refrigerators. Journal of Food Protection, 68(7), 1421-1430.

Mjoka, J. \& Selepe, M. (2018). Assessment of food hygiene knowledge and practices among food handlers in selected hotels around uMlathuze Area. African Journal of Hospitality, Tourism and Leisure, Vol 7 (4). article_47_vol_7_4_2018.pdf

New, C. Y., Ubong, A., Premarathne, J. M., Thung, T. Y., Lee, R., Chang, W. S., Loo, Y. Y., Kwan, S. Y., Tan, C. W., Kuan, C. H., Son, R. (2017). Microbiological food safety in Malaysia from the academician's perspective. Food Research Rynnye Lyan Resources, 1(6), 183-202.

Norazla, A, W., Nor Atirah, I. (2019). Penguatkuasaan Undang-Undang Terhadap Pengendalian Kebersihan Makanan dan Keselamatan di Kantin Sekolah. $5^{\text {th }}$ Muzakarah Fiqh \& International Fiqh $\quad$ Conference $2019 . \quad$ MFIFC2019EProceedingPenguatkuasaan undangundang_Norazla_Abdul_Wahab.pdf

Pejabat Kesihatan Daerah Betong. (2019). Statistical data of food poisoning between years 2014-2018.

Ramful, K., Menon, H. (2017). Food Safety and Good Hygiene Practices Handbook for Gambian Youth Entrepreneurs. Geneva: International Trade Centre.

Sharif, L., Obaidat, M., Al-Dalalah, M. (2013). Food Hygiene Knowledge, Attitude and Practices of the Food Handlers in the Military Hospitals. Food and Nutrition Sciences Scientific Research, 4, 245-251.

Sharifa Ezat, W. P., Netty, D., Sangaran, G. (2013). Paper review of factors, surveillance and burden of food borne disease outbreak in Malaysia. Malaysian Journal of Public Health Medicine, 13(2), 98-105.

Soon, J. M., Singh, H., Baines, R. (2011). Foodborne diseases in Malaysia: A review. Elsevier, 22, 823-830.

Tan, S. L., Cheng, P. L., Soon, H. K., Ghazali, H., Mahyudin, N. A. (2013). A qualitative study on personal hygiene knowledge and practices among food handlers at selected primary schools in Klang valley area, Selangor, Malaysia. International Food Research Journal, 20(1), 71-76. 30444.pdf (upm.edu.my) 
Venter, T. (2000). Emerging food-borne diseases: a global responsibility. Food and Agriculture Organization of the United Nations, 4-13.

World Health Organization. (2019). Food Borne Illnesses. Retrieved from https://www.who.int/ Institut Penyelidikan Tingkahlaku Kesihatan (IPTK) 2017. Kajian Penyertaan Pemerkasaan Pengguna (Consumer Participation Empowerment) Keselamatan Makanan di Sekolah Rendah Peringkat Kebangsaan di Bawah Asean Expert Group Food Safety (AEGFS), Kementerian Kesihatan Malaysia. 